\title{
HET WERK VAN DE EVANGELISCHE BROEDERGEMEENTE IN SURINAME
}

DOOR

\author{
B. J. C. RIJNDERS
}

Onvergetelijk is de aanblik van Suriname, wanneer ge na een reis van 19 dagen de Surinamerivier opstoomt, die omzoomd wordt door mangroven en rhizophoren, afgewisseld door koningspalmen, met hun statige kruinen, en ge dan onder het stralende zonlicht Paramaribo ziet liggen.

Wondermooi is de plantengroei van dit land waar de schoonste orchideeën en andere tropische gewassen het oog bekoren. Heerlijk zijn de vruchten, de sappige producten van dit tropenland. En toch, wanneer men er enige maanden vertoeft, verstaat men de opmerking van Mr. A. van Traa in diens verleden jaar verschenen boek over Suriname: „Hoe zal het mogelijk zijn dit eertijds welvarende land uit zijn verval op te heffen?" Deze vraag teekent de tegenwoordige toestand van Suriname en beheerst het geheele leven van dit land.

Immers dit land, dat vijf maal zo groot is als Nederland, telt niet meer dan ongeveer 180000 inwoners, waarvan ruim 50000 in Paramaribo wonen. Wanneer men de Bosnegers en Indianen in het binnenland niet mee rekent, komt men tot een bevolkingsdichtheid van 48 per vierkante geografische mijl, terwijl Nederland een bevolkingsdichtheid heeft van 120 co per vierkante G. M. en Java van 14600.

Het bevolkingsvraagstuk, van belang voor de economische ontwikkeling van het land, heeft ook zijn invloed op het morele en geestelijke peil, waarop de bevolking, bestaande uit zoveel verschillende rassen, staat. Deze invloed is duidelijk merkbaar. Vandaar dat het van zulk een groot belang is, dat Nederland en Suriname trachten de weg te vinden, om dit mooie tropenland economisch uit het moeras te helpen, maar niet minder, dat er geestelijk gearbeid wordt aan de verschillende volken in Surina- 
me. Toen ik het voorrecht had in 1946 in Suriname te zijn, heb $\mathrm{ik}$ van de arbeid der Evangelische Broedergemeente veel mogen zien: arbeid onder Creolen, Javanen, Hindostani, en Bosnegers; onder kinderen en volwassenen, onder zieken en gezonden. Ik acht het een voorrecht hiervan mijn indrukken te mogen weergeven.

Deze zendingsarbeid is reeds meer dan tweehonderd jaren geleden begonnen van Herrnhut (in Saksen) uit, de stichting van Graaf Von Zinzendorf, en de bakermat van de broedergemeente over de gehele wereld. In 1793 werd te Zeist opgericht een hulpgenootschap voor het zendingswerk in Suriname. Toen in 1928, als gevolg van wereldoorlog en inflatie, de last voor de zendingsdirectie te Herrnhut te zwaar werd, heeft het zendingsgenootschap der Evangelische Broedergemeente te Zeist de gehele verantwoordelijkheid voor de zendingsarbeid in Suriname overgenomen.

Wij willen nu samen een rondreis maken door Suriname, om met de verschillende takken van arbeid van de Broedergemeente in aanraking te komen. Wij beginnen met een wandeling door Paramaribo. Veel moois is er aan de stad niet te zien. Stenen gebouwen zijn er bijna niet. Alles hout en dan nu, na de oorlog, voor het grootste deel erg verveloos. En toch gaat er een zekere bekoring uit van die straten met hoge koningspalmen en brede mahoniebomen, van die markt, waar de marktvrouwen in haar kleurige gewaden u een keur van vruchten, groenten en andere heerlijke en nuttige dingen aanprijzen, een bont gewemel van allerlei landaarden door elkander.

In deze stad werkt de zending der Broedergemeente onder de Creolen.

Reeds in 1735 was de Broedergemeente begonnen met de evangelieprediking onder de slaven op de plantages. Deze arbeid is voortgezet tot 1863 , het jaar van de opheffing der slavernij.

Uit dit werk is voortgekomen de Creolenkerk, die haar meeste leden in Paramaribo telt. Wanneer men thans de zes kerken ziet en de statistiek van 1944 ons vertelt, dat het aantal leden der gemeente in Paramaribo 19531 is en de districten 12059, tesamen 31590, tegen 26245 in 1937, dan kan men spreken van een uitwendige groei. Mijn indruk is echter niet, dat met die uitwendige groei de inwendige gelijke tred heeft gehouden. De opkomst in de kerken is, behalve op hoogtijdagen, gering. Behoudens een kleine kern zijn er veel ,,dede Arnitri's”, dode leden der gemeente, die alleen door een uitwendige band nog aan de gemeente verbonden zijn. 
Wat is hiervan de oorzaak? Zijn dit de de schaduwzijden van een volkskerk, die zich beginnen te vertonen? Is er niet met geloof en ijver gewerkt?

Dit laatste zeer zeker! Er was en is nog trouwe dienst, waarover straks meer te zeggen valt; er is zegen op het werk, maar het feit, dat er veel dode leden der gemeente zijn vindt, afgezien van de tegenstand van het menselijk hart tegen het Evangelie, als eerste oorzaak, zijn reden in verschillende omstandigheden. Allereerst het gebrek aan voldoende arbeidskrachten in de zending. Wanneer men in het boek van Dr. Steinberg Ons Suriname de foto ziet met 43 arbeiders, alle Europese krachten, die in 1897 werkzaam waren op het zendingsveld, en nu ziet hoe er in Paramaribo slechts 7 Europese en Surinaamse predikanten werken, terwijl Paramaribo het grootste gedeelte van de Creolenkerk herbergt, begrijpt men dat het contact tussen voorgangers en gemeenteleden niet voldoende is. Daarbij komt, dat de verplaatsing van de bevolking van het platteland naar de stad nog niet tot stilstand is gekomen.

Daarbij bedenke men, dat, volgens de gegevens van Mr. van Traa, ongeveer $48 \%$ van de bevolking van Suriname uit kleinlandbouwers bestaat, een categorie die uiteraard weinig of niet draagkrachtig is, terwijl van de overige $52 \%$ het grootste gedeelte tot de on-en minvermogenden behoort. Men zou kunnen vragen: Wat heeft dat te maken met de geestelijke toestand der gemeente? Zeer veel. Want de slechte economische toestand der bevolking in Paramaribo heeft een zeer funeste invloed op het morele en geestelijke leven der gemeente. Het feit, dat er in Paramaribo 3000 eenkamerwoningen zijn, spreekt boekdelen. Als erfenis van den slaventijd zijn bovendien bijgeloof en losbandigheid nog niet verdwenen.

Dit alles maakt, dat de arbeid der Ev. Broedergemeente dringend versterking behoeft van arbeidskrachten, en aan het vraagstuk van opleiding van inheemse krachten alle aandacht moet worden besteed.

Deze Creolenkerk in Suriname stond tot 1946 nog steeds onder het bestuur van Zeist, maar de gedachte aan zelfstandigheid kwam telkens meer naar voren in de loop der jaren. Reeds in het Handboek van 1931 waren vele bevoegdheden van Zeist overgegaan op Suriname. En toen in 1942 de driejaarlijkse kerkconferentie in Paramaribo werd gehouden, kwamen de Surinaamse broeders met een voorstel tot zelfstandigheid, dat evenwel, door gebrek aan alle contact met Zeist, niet in behandeling 
kon worden genomen. Het bestuur van het Zeister zendingsgenootschap had echter met het oog op de kerkconferentie in 1946 een uitgewerkt voorstel opgesteld, om de Creolenkerk in Suriname zelfstandig te verklaren. Tot begrip hiervan is het nodig ons de ingewikkelde situatie in Suriname voor ogen te stellen. In Suriname is een Creolenkerk, zoals we reeds zagen, ontstaan uit de zendingsarbeid onder de slaven, en na 1863 onder de vrije Creolen. Daarnaast is uit de arbeid onder de Hindostani gegroeid een Hindostanigemeente, en uit de arbeid onder de Javanen een Javaanse kerk. Met het voorstel van Zeist lag nu de bedoeling voor, dat de Creolenkerk zelfstandig zou worden, en tevens de Boslandzending voor haar rekening zou nemen, terwijl het werk onder de Hindostani en Javanen geheel onder de leiding van Zeist zou blijven.

Het bleek echter spoedig, toen de twee bestuursleden van het Z.Z.G. in Paramaribo met verschillende Surinamers daarover besprekingen voerden, dat bij hen een andere gedachte voorlag. Immers de christen-Javanen en -Hindostani en -Bosnegers zijn ook leden van de Evangelische Broedergemeente, en men vreesde, dat bij een zelfstandigverklaring van de Creolenkerk, met uitsluiting van de andere, de eenheid zou worden verbroken. En men verlangde juist die eenheid in de nieuwe plannen te behouden. Dit leidde na zeer veel besprekingen tot een nieuw plan, n.l. de zelfstandigverklaring van de gehele Evangelische Broedergemeente in Suriname.

Maar met deze gedachte kwamen zeer veel problemen naar voren. Hoe zal de verhouding zijn van deze Creolenkerk tot het Zeister Zendingsbestuur daar de nieuwe kerk niet financieel in staat is de Aziatenzending, en zelfs niet de gehele Boslandzending te bekostigen? $\mathrm{Al}$ is er hoop, dat eenmaal de Broedergemeente voor zichzelf en het zendingswerk zal kunnen zorgen, momenteel is daarvan nog geen sprake. Vandaar, dat er, rekening houdende met al deze problemen, besloten is tot een zelfstandige Evangelische Broedergemeente in Suriname in overgangstijd, en in een afzonderlijke overeenkomst, dus niet in de kerkorde, de verhouding met Zeist is vastgelegd. Deze zelfstandige kerk kiest haar eigen Synode, welke Synode het Kerkbestuur voor de lopende zaken kiest, met dien verstande, dat daarin steeds een zendeling van de Hindostani en van de Javanen zitting heeft. By dit alles komt dadelijk de vraag naar voren, of het gewenst is een kerk zelfstandig te verklaren, zolang ze niet voldoet aan de drievoudige eis van zelfonderhoud, zelf- 
regering, en zelfuitbreiding, maar Java heeft ons voldoende getoond, ondanks de bezwaren, die geopperd werden, toen Prof. Kramer er op aandrong de Oost-Javaanse kerk zelfstandigheid te geven, dat ook bij niet-voldoen aan al de drie eisen, toch het tijdstip kan gekomen zijn, om zulk een kerk zelfstandig te verklaren.

Wanneer wij nu onze blik slaan op de districten buiten Paramaribo, en aldaar het kerkelijk leven in ogenschouw nemen, zij allereerst opgemerkt, dat de bewoners van de verschillende districten een duidelijk verschil van mentaliteit vertonen. De bewoners van de Para, Coronie en Nickerie zijn evenveel verschillende typen van mensen. Nickerie en Coronie zijn echte centra, waar de mensen dicht op elkaar wonen, Moengo is een industrieplaats van de Bauxietmaatschappij. De andere districten zijn reisdistricten. De leraar moet uren en uren varen langs de rivieren, om zijn filiaalgemeenten te bereiken, die vaak even klein of even groot zijn als de hoofdgemeenten. Wel valt het daarbij op dat juist in die reisdistricten het christendom in alle eenvoud dieper en echter geworteld is, of, om het te zeggen met de woorden van een der jaarverslagen: er de meeste goede Herrnhutters gevonden worden.

Met welke moeilijkheden de zending hier te worstelen heeft, kan het beste worden gedemonstreerd met het volgende voorbeeld.

Charlottenburg is een der oudste posten der zending in Suriname. Reeds in 1835 werd hier het werk begonnen. Ge ziet er een kerk en een school en een grote zendelingswoning, waar vroeger drie zendelingsgezinnen woonden, die daar overvloedig werk vonden. En nu? Het huis staat onbewoond. De gehele streek is ontvolkt. Toen in de loop der jaren na de opheffing der slavernij de mensen niet langer als vrijen op de plantages wilden werken, waar ze steeds als slaven gearbeid hadden, en bovendien langzamerhand de plantages te gronde gingen door ziekte in de cacao en koffie, vertrok de bevolking naar elders, en werd de trek naar de stad steeds groter. Dit stelt de zending voor de vraag: Wat moeten wij beginnen met zulke posten als niet Charlottenburg alleen maar ook Potribo en Wanhatti? Hoe moet men de verspreide bevolking benaderen en bewerken? Meer evangelisten opleiden, maar waar zijn de middelen, terwijl het leven in Suriname steeds duurder wordt, en bovendien de ongunstige wisselkoers (100 Sur. guldens $=142$ Hollandsche guldens) de zending parten speelt. Er zijn voor de kleine christengroepen wel onder- 
wijzers, die des morgens voor de klas staan, en daarna geestelijk werk in de gemeente verrichten, maar zij zijn niet in staat zelfs de ouders van hun kinderen te bezoeken. Onder de kinderen, die in Potribo op school gaan, zijn er, die drie en een half uur roeien moeten in een kleine korjaal om van huis naar school te komen en dan terug weer dezelfde afstand moeten afleggen.

Voordat wij van de zending onder de Creolen afscheid nemen, zij nog gewezen op het kinderhuis Saron, gelegen aan de rand van Paramaribo, waar een 70tal creolenkinderen wordt verzorgd en opgevoed. In 1911 werd dit kinderhuis gesticht, dat zijn plaats in de samenleving al heeft veroverd, en in een grote behoefte voorziet.

Wanneer wij voor onze geest de rij der rassen laten passeren, waaronder de Broedergemeente gewerkt heeft of werkt, willen wij even memoreren, dat helaas van de arbeid onder de Indianen, zoals die van 1738-1808 geschiedde in Berbice en Suriname niets meer over is. Wel worden nog enkele protestantse Indianen van Nieuw Nickerie uit op bepaalde tijden bezocht, maar van de drie posten die er vroeger waren, is niets meer over. De meeste Indianen behoren thans tot de R.K. Kerk. De ver in het binnenland, gedeeltelijk pas ontdekte, stammen, zijn nog nooit in aanraking met het Evangelie geweest.

$\mathrm{Na}$ de opheffing der slavernij heeft men, zoals bekend, het nijpend gebrek aan arbeidskrachten trachten te ondervangen door het invoeren van Brits-Indische arbeidskrachten. Meer dan 34000 contractanten werden naar onze West vervoerd. Het aantal beloopt tegenwoordig meer dan 45000 , dat is $25 \%$ der bevolking. Wanneer wij zien, hoe zij zich nu gedeeltelijk als landbouwers hebben gevestigd en b.v. in Nickerie grote rijstvelden hebben aangelegd, gedeeltelijk zich in de handel een plaats hebben veroverd, is het niet te verwonderen, wanneer men meent, dat dit energieke volk in de toekomst een grote, zo niet de plaats in Suriname zal innemen. Zij zijn voor 85\% Hindoes en voor $15 \%$ Mohammedanen.

In 1901 is het werk onder hen door de Broedergemeente begonnen. Deze arbeid, tot heden voortgezet, was en is niet gemakgelijk.

Het Hindoeisme leert, dat de wereldgeschiedenis ook het wereldoordeel is. In de loop der zielsverhuizing krijgt ieder op deze wereld zijn loon en maakt hij tegelijk zijn toekomst. Vandaar vaak fanatieke tegenwerking der Hindoes, want in de lijn van 
deze gedachtengang is de ergste zonde: over te gaan tot het Christendom. Toch is er vrucht op de arbeid.

De Brits-Indische gemeente telt ongeveer 400 leden volgens de statistiek van 1944. Verschillende posten aan de rivieren worden door Brits-Indische evangelisten verzorgd. Buitengewoon te betreuren is het, dat voor dit werk, dat zoveel perspectieven biedt, slechts één zendeling staat, terwijl er minstens drie Europese zendelingen moesten zijn. Ook hier is nood aan arbeidskrachten, en aan middelen, om deze te doen opleiden en te salarieren.

Ook deze zending heeft een tehuis voor Brits-Indische kinderen, dat in Alkmaar ligt aan de Commewijne. Een idyllisch plekje. Dit tehuis, dat steeds overvol is, wordt voor een gedeelte door Deense zendingsvrienden bekostigd.

Ook Javanen vindt men in Suriname. Spoedig na de invoer van Brits-Indiërs is men met het invoeren van Javanen als contractanten begonnen ten getale van een 30000. Deze waren niet alle volwaardige arbeidskrachten. In 1905 werd de zendingsarbeid onder hen door de Broedergemeente begonnen, nadat men eerst een poging had gedaan, een Nederlandse zendingscorporatie er toe te bewegen, deze arbeid onder de Javanen te beginnen, welke poging echter geheel mislukte.

Deze arbeid onder de Javanen is wel een van de meest moeilijke, maar daarom niet minder gezegend.

De Javaan in Suriname kenmerkt zich door onverschilligheid op godsdienstig gebied, en zijn Mohammedaans geloof raakt zijn hart en zijn leven niet, en ondanks dat zien we, dat de verhouding, van Christenen tot niet Christenen onder de Javanen is $1: 100$, een verhouding die men op geen enkel ander Mohammedaans zendingsveld aantreft.

Wat bovenal treft is, dat zoveel jonge mensen tot die kleine Javaanse gemeenten behoren, die ondanks de tegenstand van de Javaanse bevolking standvastig blijven.

Op de post Leliëndaal staat een kinderhuis voor Javaanse kinderen, ook al geheel gevuld. Momenteel werken er onder de Javanen twee Hollandse zendelingen, waarvan één nu met verlof in het vaderland is. Ook hier zijn meer krachten nodig om goeroes op te leiden en te leiden.

Het zendingswerk onder de Aziaten heeft mede daardoor zijn eigenaardig karakter, dat de bevolking niet geheel uit gezeten burgers bestaat. Er is veel heen en weer trekken en daardoor veel verandering in de gemeenten. 
Van zeer grote betekenis is ook de arbeid onder de Bosnegers. Deze zendingsarbeid heeft zijn bepaald karakter door de strijd met de goden van bloed (voorouders) en van bodem (grond, natuur).

De tegenwoordige Bosnegers zijn de nakomelingen van de zgn. Marrons (weglopers), die zich door ontvluchting aan de slavernij onttrokken en zich in de bossen verscholen. In 1765 begon de Broedergemeente op verzoek van de toenmalige gouverneur Crommelin haar arbeid onder hen, en deze arbeid is sedert die tijd onafgebroken doorgegaan. Reeds spoedig bleek, en menig graf in het Bosland getuigt daarvan, dat Europese zendelingen het klimaat niet kunnen verdragen. Vandaar dat deze arbeid door inheemse krachten wordt verricht. Schrijver dezes heeft in October 1946 in Paramaribo met de evangelisten uit het Bosland vergaderd, en de grootste eerbied gekregen voor deze pioniers, die onder allerlei gevaren van lichamelijke (ziekten, besmetting) en geestelijke (van tooverdokters enz.) tegenstand hun werk in het oerwoud verrichten. Uit hun mededelingen en uit de jaarverslagen blijkt, dat de gemeenten aan de Boven-Saramaca (Matoearis) meer het karakter van christendorpen vertonen dan die aan de andere rivieren. In de meeste dorpen aan de Boven-Suriname (Saramaccanen) is dit heel anders. In totaal zijn er ongeveer 3000 Christenbosnegers op een sterkte van ongeveer 17 à 18000 Bosnegers.

Broodnodig moeten meer evangelisten voor dit werk worden opgeleid, daar het aantal der werkers veel te klein is, en er steeds een zekere reserve voorhanden moet zijn, daar telkenmale blijkt, dat ook van de inheemse werkers vele niet tegen het klimaat van het Bosland bestand zijn. Een eresaluut aan hen, die hun leven geven voor deze arbeid in het oerwoud.

In dit verband mag er nog wel op gewezen worden, dat de verschillende Surinaamse predikanten in Paramaribo zijn aangewezen, om enige malen in het jaar een hun toegewezen deel van het Bosland te bereizen voor inspectie en het toedienen van de sacramenten, wat hen zeker twee maanden in het jaar aan hun werk in eigen gemeente onttrekt. De bedoeling is nu een Europese predikant van de staf der werkers speciaal als inspecteur voor het werk in het bosland aan te stellen, wat een ontlasting van het werk zal zijn voor de andere predikanten.

De gezondheidstoestand onder de Bosnegers is over het algemeen slecht. In een rapport, door den voorzitter van het Zeister zendingsgenootschap uitgebracht aan de geneeskundige inspec- 
teur te Pa:amaribo naar aanleiding van een tweetal reizen langs de Boven-Saramacca en de Boven-Suriname, lezen wij, dat, hoewel de gezondheidstoestand in de christendorpen aan de BovenSaramacca niet slecht is te noemen, er door inteelt en waarschijnlijk andere oorzaken schrikbarend weinig kinderen worden geboren. Men schat, dat $40 \%$ van alle huwelijken kinderloos is, $40 \%$ met een of twee kinderen gezegend en 30\% met meer dan twee kinderen, maar zeer zelden met meer dan drie of vier. Dat bovendien $60 \%$ der geboren kinderen reeds als baby sterft. Indien hier geen hulp komt, zal dit volk uitsterven.

Aan de Boven-Suriname is de toestand anders. Abnormaal veel kinderen worden hier geboren, maar de kindersterfte, gedurende het eerste levensjaar ligt niet ver beneden de $70 \%$.

Daar heerst de lepra en de melaatsen lopen zonder enige isolatie in de dorpen rond. Yaws (framboesia) is er in schrikbarende mate. Mijnwormziekte, oogziekten, venerische ziekten teisteren de bevolking. De medicijnen, die de evangelisten van het gouvernement krijgen, zijn bedoeld voor een heel jaar en voldoende voor een of twee weken. Medische verzorging van het gouvernement is er verder in het Bosland niet.

De Broedergemeente had onder de indruk van deze toestanden reeds enige jaren vóór de oorlog een bescheiden aanvang gemaakt met medisch werk door te Ganzee een zusterhuis en een hospitaaltje te bouwen, waar Zr. Nellie de Borst als eerste Europese vrouw in deze eeuw zich aan die arbeid heeft gegeven, en met grote liefde en zelfverloochening daar tot geestelijk en lichamelijk welzijn der Bosnegers heeft gewerkt. Tenslotte kon zij het ook niet volhouden en heeft het werk enkele jaren stilgestaan. Maar thans is met hulp van Simavi een groter plan in wording, nu dokter P. A. de Groot met twee verpleegsters onder de Bosnegers gaat arbeiden en daartoe te Kabel een bescheiden hospitaal met zusterhuis en dokterswoning zal worden gebouwd, waarvoor gerekend wordt op de steun van het gouvernement en de bevolking van Suriname. Te vroeg is het niet, dat er wat aan de medische verzorging der Bosnegers wordt gedaan!

Ten slotte is er nog een tak van arbeid, die we niet genoemd hebben en die toch van buitengewone betekenis is voor het geheel van het werk, n.l. de schoolarbeid. Deze heeft zich in de loop der jaren zeer uitgebreid. Het is interessant om de groei van het onderwijs te volgen van 1738 af, toen een aanvang werd gemaakt met het onderwijs aan slavenkinderen te Poelgeest in Berbice, tot op heden. In 1935 bedroeg het aantal leerkrachten 
aan de scholen der Broedergemeente in Suriname 179 met 6959 leerlingen. Het cijfer der leerlingen is nu reeds de 9000 voorbij, en de vraag naar onderwijs der Broedergemeente neemt toe. Dit alles brengt echter voor de Broedergemeente moeilijkheden mede, omdat door deze aanwas verschillende scholen te klein zijn geworden (ik zag eens op een bank voor twee kinderen er vijf zitten!) en om verbouwing vragen, terwijl andere scholen geheel vernieuwd moeten worden. Waar in Suriname nog niet die volstrekte gelijkstelling van onderwijs is, als men hier in Nederland kent, blijven vele zorgen voor rekening van de Broedergemeente. Inmiddels blijft deze schoolarbeid, onder leiding van een eigen inspecteur, een zeer machtig hulpmiddel voor de verkondiging van het Evangelie. Hoe de reorganisatieplannen van het onderwijs er zullen uitzien, na het bezoek van den Heer Dàens, gevolmachtigde van de Nederlandse regering, aan Suriname, en welke gevolgen deze zullen hebben voor het onderwijs van de Broedergemeente, is nog niet te zeggen.

Van veel betekenis is ook de arbeid der stadszending in Paramaribo. Sinds 1921 beschikkend over een nieuw groot gebouw, staat de stadszending in het middelpunt der belangstelling en wordt alle arbeid: Evangelisatie, huisbezoek, verenigingswerk, jeugdwerk in de meest uitgebreide zin, centrale armenzorg, arbeidsbureau, wezenverzorging enz., onder leiding van een nieuwe directeur, met een staf, die voor zijn taak berekend is, verricht.

Deze arbeid onder jeugd en volwassenen, zieken en gezonden. kerkelijken en onkerkelijken, staat midden in het geestelijk en kerkelijk leven van Paramaribo.

En de totaalconclusie der ontvangen indrukken?

Er wordt prachtig, zegenrijk werk verricht in Suriname, maar bij de zeer vele kansen, die geboden worden, ontbreekt het aan geschoolde krachten en aan de nodige middelen. Dit moge Christelijk Nederland wel bedenken.

Is dit het laatste woord? Niet erg bemoedigend, zult ge zeggen.

Mag ik eindigen met een zeer persoonlijke ervaring?

Slechts een negental dagen was ik in Paramaribo, toen ik met de Praeses der zending een bezoek bracht aan de melaatsenkolonie Bethesda. Enkele kilometers buiten Paramaribo ligt daar het oord, waar lepralijders worden verzorgd en in aanraking worden gebracht met de grote Medicijnmeester Jezus Christus, een arbeid, waaraan alle protestantse gezindten in Suriname medewerken. 
Mooi is de aanleg van tropische boomen en gewassen waar de koningspalmen hun kruinen hoog naar den hemel verheffen. Paviljoenen voor mannen vrouwen en kinderen, woningen voor directie en zusters, kerk en school, en wat nog meer voor de verzorging van een 180 tal patiënten nodig is, staan schilderachtig gegroepeerd langs de verschillende lanen. Een afgesloten geheel, waar niemand zo maar kan binnenkomen of uitgaan. Want dit liefelijk oord bergt zoveel ellende, smart en besmetting. Een rondgang langs de open paviljoenen en een bezoek in enkele vertrekken grijpt zo aan, dat men dagenlang het beeld van de door melaatsheid verminkten voor zich blijft zien. Blinden, misvormden, vaak reeds op jeugdige leeftijd, vinden hier de lichamelijke en geestelijke verzorging, die zij behoeven.

In een der vertrekken zit een vrouw op de rand van haar bed. Zij mist het licht der oogen, haar gelaat is misvormd en haar geest is niet geheel helder meer. Als ik haar groet, begint ze te spreken en dankt voor alles wat de christenen voor haar hebben gedaan. Ze is zo dankbaar en tevreden, en telkenmale hoor ik haar de naam van Jezus uitspreken. Is ze innerlijk klaar om verder het moeilijke leven te dragen en straks in Jezus te ontslapen? Ik geloof het wel, maar zij kan het niet uiten.

Wij gaan weer verder. Buiten op een der galerijen zit een oude van dagen, ver over de zeventig, een Surinaamse, kind van het oude volk Israël. Zien kan ze niet meer, maar de ziekte heeft in haar uitgewoed, wat wel meer schijnt voor te komen. $\mathrm{Ze}$ is nog helder van geest en als ze spreken gaat is het één lofzang aan Hem, die zo goed voor haar is geweest. $\mathrm{Zij}$ heeft Gods bedoeling met haar verstaan en dankt Hem daarvoor, want zij heeft in het lijden haar plekje bij het kruis van Christus gevonden en daarin roemt zij.

En terwijl daarbuiten de tropenzon alles in helle gloed zet, vervolgen wij onze weg, geslagen door alle smart, die daar geleden wordt maar dankbaar tevens voor het werk, dat God daar doet....

Het is enige weken later in December. Weer ben ik op Bethesda. Het is avond. De maan werpt haar stralen over dit rustige oord met zijn tropische rijkdom. Ik mag nu in de kerk aan de melaatsen het Advents-evangelie brengen. Wie enigszins lopen kan, of naar de kerk vervoerd kan worden, is aanwezig. Stil wordt geluisterd naar de aloude boodschap van Christus, komst. Het lied klinkt slechts gebroken, want vele kunnen niet of nauwelijks meer zingen. Als de dienst is afgelopen en ik mij 
naar de uitgang van de kerk begeef, is daar één, die iets wil zeggen: Dominee ik ben blind, maar ik wacht op het ogenblik, dat God $\mathrm{Zijn}$ hand van mijn oogen zal wegnemen, en dan zal ik Hem zien in heerlijkheid.......

In stilte wandelen wij door de maanlichte lanen naar de uitgang. Hebben wij wel enig idee wat dit lijden betekent voor deze melaatsen, elke dag weer opnieuw? Bij vele sterven de ledematen af, maar terwijl het uitwendige vergaat, wordt ook bij velen het innerlijke vernieuwd, van dag tot dag. En wij danken God voor de les, die Hij ons te leren gaf, en verstonden het: God heeft met Suriname wat goeds voor. Dat is de kracht en bemoediging voor alle zendingsarbeiders en -arbeidsters in Suriname. 